\title{
Placement of leads for stereotactic electroencephalography without the use of anchor bolts: technical note
}

\author{
Torin Karsonovich, DO,,2 Allyson Alexander, MD, PhD, ${ }^{1,3}$ Sarah Graber, BA,,4 and \\ Brent R. O'Neill, MD',3
}

${ }^{1}$ Department of Neurosurgery, ${ }^{2}$ Advocate Bromenn Medical Center, Normal, Illinois; ${ }^{3}$ Children's Hospital of Colorado, Aurora; and ${ }^{4}$ Neuroscience Administration Research Team, Aurora, Colorado

\begin{abstract}
OBJECTIVE Stereotactic electroencephalography (SEEG) is an increasingly common technique that neurosurgeons use to help identify the epileptogenic zone. The anchor bolt, which typically secures the electrode to the skull, can be problematic in very thin bone or in electrodes placed in the occiput.

METHODS A technique is described to place electrodes without the use of an anchor bolt. Accuracy data for entry point, target point, and depth were collected and compared between electrodes placed with and those placed without an anchor bolt.
\end{abstract}

RESULTS A total of 58 patients underwent placement of 793 electrodes, of which 25 were boltless. The mean entry and depth errors at target were equivalent, although there was a trend toward greater depth error with boltless electrodes ( $3.4 \mathrm{~mm}$ vs $2.01 \mathrm{~mm}$ and $2.59 \mathrm{~mm}$ in the bolted groups, respectively). The mean lateral target error was slightly but significantly smaller for boltless electrodes. The majority $(60 \%)$ of boltless leads were placed into thin temporal squamous bone. The average skull thickness at the entry point for all boltless leads was $1.85 \mathrm{~mm}$.

CONCLUSIONS Boltless SEEG electrodes can be placed through thin bone, adjacent to a cranial defect, or in the occiput with equivalent accuracy to electrodes placed with anchor bolts.

https://thejns.org/doi/abs/10.3171/2020.7.PEDS20403

KEYWORDS epilepsy; stereotactic electroencephalography; SEEG; boltless electrodes; surgical technique

$\mathrm{E}$ PILEPSY is a common condition in adult and pediatric patients, affecting at least 50 million people worldwide. $^{1-3}$ Unfortunately, approximately $20 \%-40 \%$ of patients with epilepsy continue to have seizures despite appropriate antiepileptic drug therapy. ${ }^{4-8}$ These patients often undergo extensive noninvasive workups, including MRI, scalp electroencephalography (EEG), video-EEG, PET, magnetoencephalography, and SPECT, ${ }^{9,10}$ without precise localization of the epileptogenic zone (EZ). The EZ is often defined as the "minimum amount of cortex that must be resected (inactivated or completely disconnected) to produce seizure freedom." ${ }^{11}$ When noninvasive imaging modalities fail to localize the EZ, invasive modalities such as stereotactic EEG (SEEG) or subdural grid placement are commonly used..$^{12}$ SEEG first became popularized in France in the 1950s by Talairach and colleagues ${ }^{13}$ and has since been refined using newer stereotactic techniques, including surgical robots. ${ }^{14-20}$

Current SEEG systems rely on an anchor bolt, also known as a guide screw or bolt to hold each electrode in place and to maintain the appropriate trajectory. The anchor bolt is a thin, hollow metal shaft that is threaded on both ends. The portion proximal to the patient threads into the bone, providing secure purchase to keep the electrode in place and to direct it along the proper trajectory. The distal threading connects with the electrode cap to secure the electrode's depth and prevent leakage of cerebrospinal fluid. An issue may arise when a planned trajectory passes through very thin bone that offers little purchase for the bolt. In this scenario, the bolt can move with relatively little force, changing either the depth or the angle of the electrode.

The risk of a mobile bolt was dramatically demonstrated early in our SEEG experience when a hemorrhage resulted 9 days after electrode implantation. The patient was an 18 -year-old male with suspected perisylvian epilepsy. He had undergone grid placement at 7 years of age without subsequent resection due to a lack of seizures during the monitoring period. Due to his prior craniotomy, his skull had several areas of thin bone and small bony defects. Electrode implantation proceeded smoothly, although sev- 

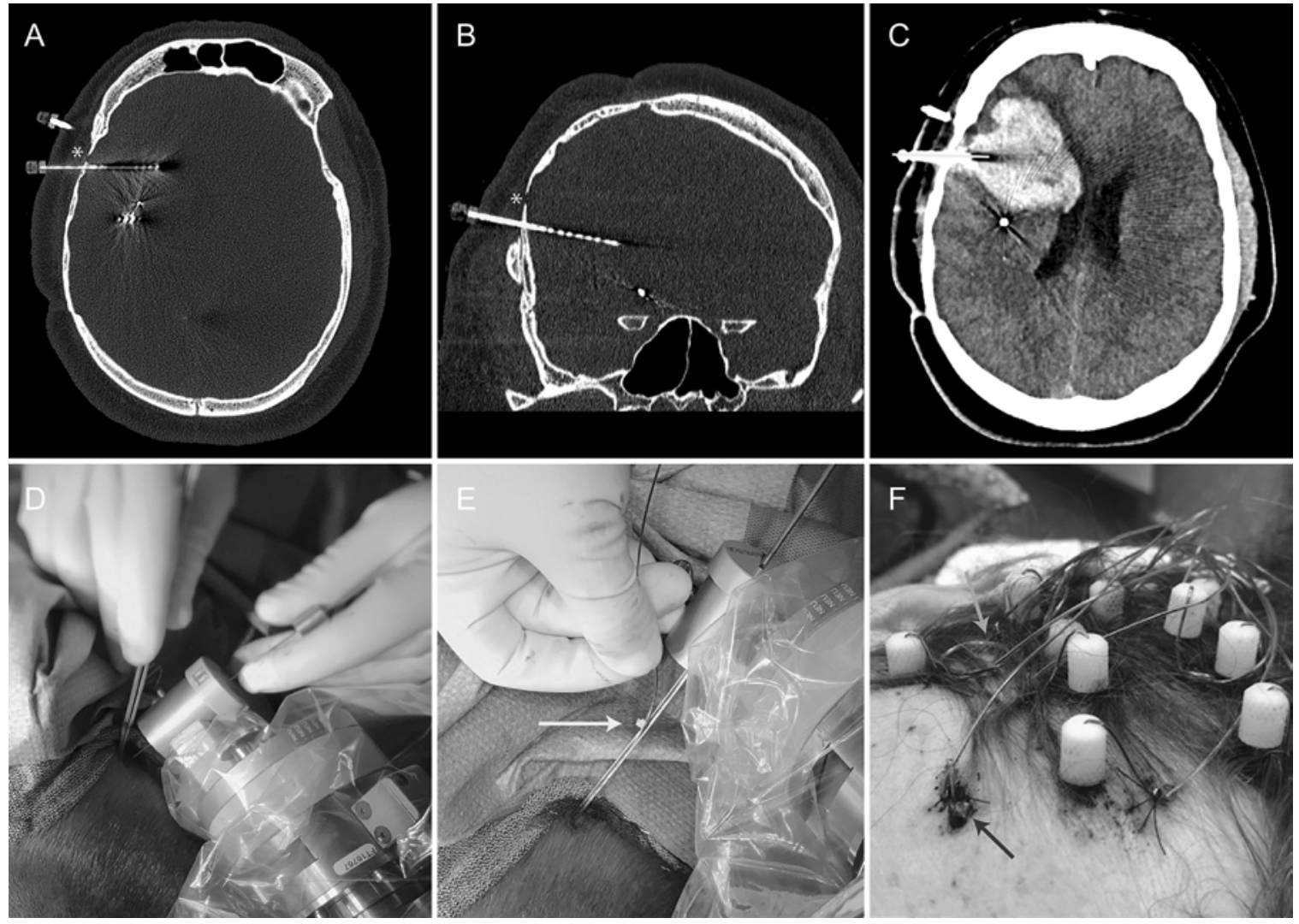

FIG. 1. An 18-year-old patient with a prior craniotomy for grid placement underwent SEEG. A and B: CT scans obtained immediately postoperatively showing bolt placement adjacent to the prior craniotomy site (asterisks) without hemorrhage. The bone is 2 $\mathrm{mm}$ thick. C: CT scan obtained 9 days later showing intraparenchymal hemorrhage due to bolt movement. D-F: Operative steps for boltless technique. After creation of a twist-drill hole, the stylet is passed to the intracerebral target, creating a track through the parenchyma (D). The split cannula is docked to the cranial opening, and the electrode is passed down (E). The proper depth is marked with an adhesive surgical tape strip (arrow; E). The electrode is tied in a knot and secured to the skin with a nylon suture (arrows; F). Figure is available in color online only.

eral bolts seemed slightly loose. A routine postoperative CT scan showed good placement of the electrodes without hemorrhage (Fig. 1A and B). After 9 days of monitoring, the EEG tracings flattened, starting at the proximal contacts of the frontal-insular electrode and spreading rapidly. The patient then developed confusion and vomiting. A CT scan showed a large frontal lobe hemorrhage adjacent to the frontal-insular bolt (Fig. 1C). On removal of the electrodes the same day, the offending bolt was found to be loose, toggling quite freely within the bone. Review of the planning revealed a large surface vein several millimeters away from the bolt, the skull measuring $2.1 \mathrm{~mm}$ in thickness at the bolt entry site, and an adjacent bony defect. Our conclusion was that slight movement of the bolt caused further loosening and eventually led to injury of the adjacent cortical vein. As a result, we developed a technique for placing electrodes without a bolt and present this technique along with data analyzing the accuracy of boltless leads.

\section{Methods}

\section{Data Collection and Analysis}

After receiving approval from the institutional review board at the University of Colorado, Anschutz Medical
Campus, we retrospectively analyzed error data that were collected prospectively in all patients undergoing SEEG placement at our institution since the inception of the SEEG program in May 2015. All cases were performed by the two senior authors (A.A. and B.R.O.). The skull thickness was measured retrospectively at the entry site for all boltless electrodes on postoperative CT or O-arm scans. The rationale for using the boltless technique was retrospectively categorized for each electrode.

\section{Error Measurements}

All patients undergo immediate postoperative $\mathrm{CT}$ or $\mathrm{O}$-arm scanning to document electrode location. The CT scan is merged with preoperative MRI, and electrode accuracy is assessed and recorded shortly after the procedure. Accuracy is determined by three measurements, rounded to the nearest millimeter. Entry point error is determined according to the distance between the planned and actual entry points in the plane perpendicular to the electrode. Target point error is determined in the same fashion but at the planned target point. Depth error is the difference between the planned and actual electrode endpoints measured in line with the planned trajectory (the 
TABLE 1. Demographic and clinical information based on implantation strategy

\begin{tabular}{|c|c|c|c|c|c|}
\hline & All & CRW Bolted & ROSA Bolted & ROSA Boltless & $\mathrm{p}$ Value \\
\hline No. of patients (\%) & 58 & $5(8.62)$ & $48(74.14)$ & $10(17.24)$ & \\
\hline Female & $20(34.5)$ & $2(40)$ & $14(32.5)$ & $4(40)$ & \\
\hline Male & $38(65.5)$ & $3(60)$ & $29(67.4)$ & $6(60)$ & \\
\hline Mean age, yrs & $13.4 \pm 4.3(1-19)$ & $13.8 \pm 3.9(7-17)$ & $13.84 \pm 4.2(1-19)$ & $11.1 \pm 4.8(3-19)$ & $0.19^{*}$ \\
\hline No. of patients w/ prior cranial surgery (\%) & $15(25.9)$ & $1(20)$ & $12(25)$ & $2(20)$ & $>0.99 \dagger$ \\
\hline Mean no. of electrodes per primary implantation & $13.05 \pm 2.51(7-21)$ & $12.6 \pm 0.55(12-13)$ & $12.86 \pm 2.76(7-21)$ & $14.10 \pm 1.66(11-16)$ & $0.24^{*}$ \\
\hline \multicolumn{5}{|l|}{ Implantation side, $\mathrm{n}(\%)$} & \multirow{4}{*}{$0.43 \dagger$} \\
\hline Unilateral, It & $26(44.8)$ & $2(40)$ & $22(51.2)$ & $2(20)$ & \\
\hline Unilateral, rt & $20(34.5)$ & $2(40)$ & $13(30.2)$ & $5(50)$ & \\
\hline Bilateral & $12(20.7)$ & $1(20)$ & $8(18.6)$ & $3(30)$ & \\
\hline
\end{tabular}

Mean values are presented as the mean \pm SD (range). All calculations in this table are based on the first SEEG implantation per patient.

${ }^{*}$ Kruskal-Wallis test.

† Fisher's exact test.

absolute value is used for this measurement). Statistical tests were performed using GraphPad Prism or IBM SPSS (version 25, IBM Corp.), and specific tests used are noted in footnotes for the tables and figures. Three-dimensional reconstruction for figures was performed with iPlan Net (Brainlab software). Image editing for pseudocolor and image cleanup was performed using Adobe Photoshop software. Original images are available on request.

\section{Surgical Technique}

All patients received approval for SEEG monitoring by the multidisciplinary epilepsy surgery team after extensive preoperative workup. For the first 5 patients, a CRW frame (Integra) was used for electrode placement with trajectories planned on the Brainlab platform. For these 5 patients, all electrodes were placed with anchor bolts. For the remainder of the series, the ROSA robot (Zimmer Biomet) was used to plan and perform stereotaxy. PMT electrodes (PMT Corp.), $0.8 \mathrm{~mm}$ in diameter, and guide screws were used in all cases. Trajectories are planned on a postcontrast T1-weighted MRI sequence optimized to identify blood vessels. Planning is individualized based on the preimplant hypotheses of possible seizure onset zone and on the need to define margins of a potential future resection. ${ }^{17,21-25}$ The decision to place an electrode with a boltless technique is typically made intraoperatively. The boltless technique is routinely used when the bone thickness is less than $2 \mathrm{~mm}$ and is considered when the bone thickness is between 2 and $3 \mathrm{~mm}$. Electrodes placed in the back of the head were also considered for the boltless technique to allow the patient to lie supine without undue pressure on the anchor bolt.

All patients are registered to the ROSA system with bone-mounted fiducials using a CT or O-arm scan. The robotic arm is driven to the preplanned trajectory, and a stab incision is created. The bone is penetrated with a $2.4-$ or 2.1-mm drill bit, and the dura is opened. For the boltless technique, a measurement is then taken from the skin surface to the intracerebral target by placing the drill guide on the skin surface and acquiring a measurement from the ROSA. The electrode is then marked at this length with an adhesive surgical tape strip. A reducing tube is placed in the robotic arm, and the stylet is passed through it to the target (Fig. 1D), creating a track though the brain for the more malleable electrode to follow. A 2.11-mm-diameter $\times 24$ $\mathrm{cm}$ split cannula (AdTech) is placed in the robotic arm and
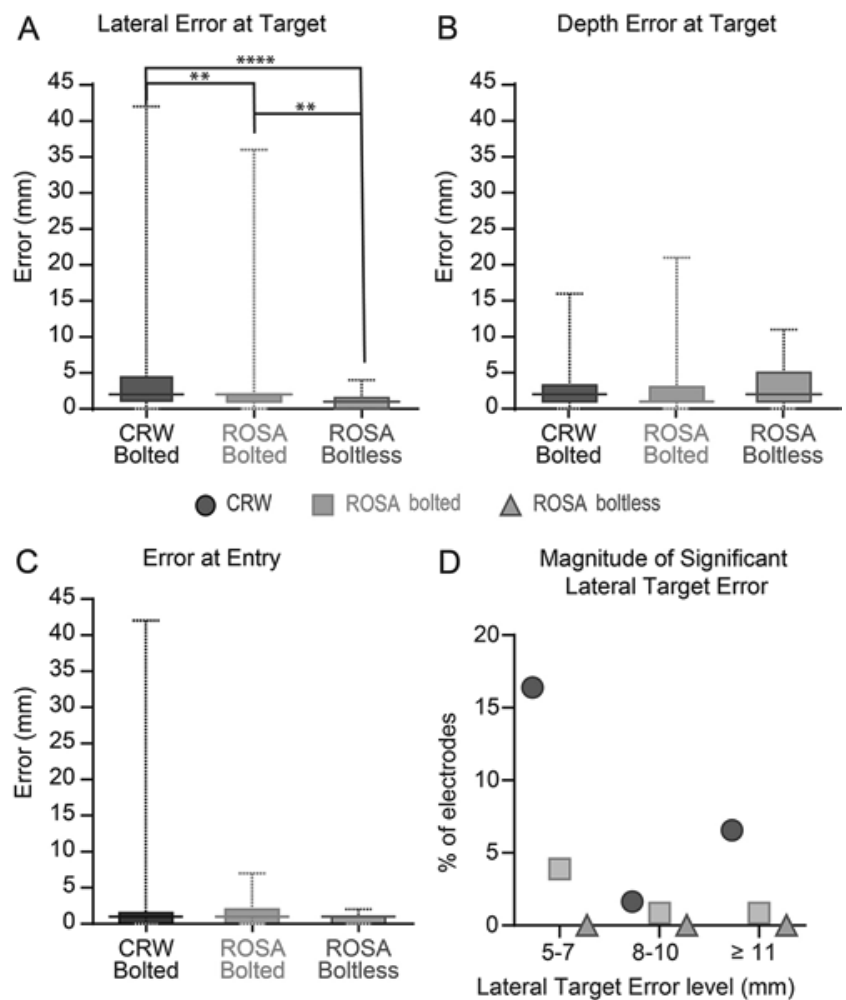

FIG. 2. Error measurements for three types of electrodes, based on placement technique. A-C: Plots demonstrate median, IQR, and range for the lateral error at target $(A)$, depth error at target $(B)$, and error at entry (C). Comparison between groups was performed with the KruskalWallis test. D: The percentage of implanted electrodes falling within three categories of significant lateral target error is plotted for each electrode placement technique. ${ }^{* *} p<0.01 ;{ }^{* * * *} p<0.0001$. Figure is available in color online only. 

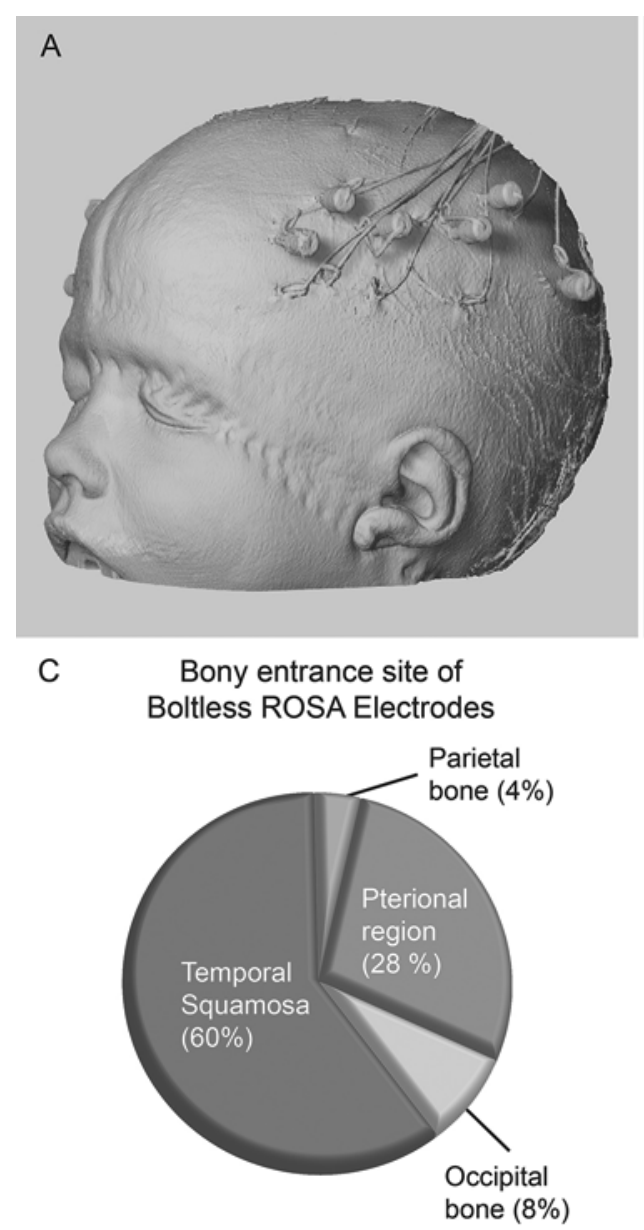

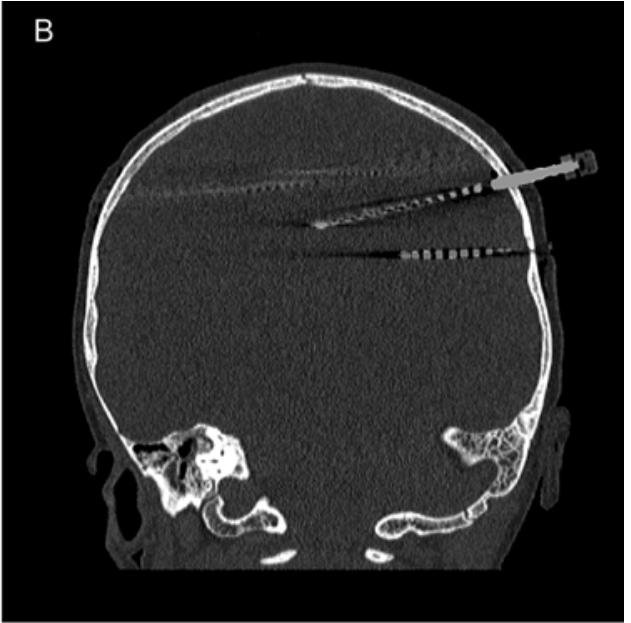

$\mathrm{D}$

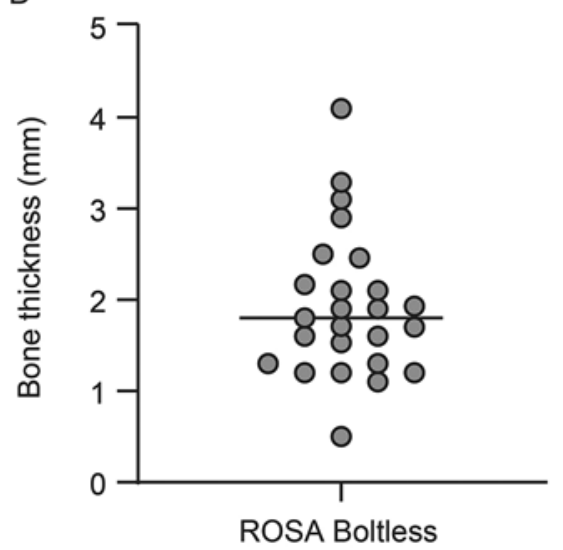

FIG. 3. A: Three-dimensional reconstruction of a postoperative CT scan demonstrating the low profile of the boltless electrodes in a 5 -year-old patient who underwent ROSA SEEG implantation of 5 boltless (blue) and 10 bolted (orange) electrodes. B: Coronal CT scan obtained in the same patient, demonstrating straight trajectories with both implantation types. C: Pie chart demonstrating the entry bone for all 25 boltless electrodes in the series. Pterional electrodes were placed in the frontal (6/7) or parietal (1/7) bones. D: Scatterplot demonstrating the bone thickness for each boltless electrode and the median value. Figure is available in color online only.

docked to the twist-drill hole, with the robotic arm backed about $20 \mathrm{~cm}$ away from the skin. It is vital to dock the split cannula to the twist-drill hole both to maintain an accurate trajectory and to allow the electrode to enter the small bony and dural openings. The electrode is then passed down the split cannula to the depth marked with the surgical tape strip (Fig. 1E). The 2.11-mm cannula is not passed to the target to minimize disruption along the track, as the diameter of the cannula is significantly wider than that of the electrode $(0.8 \mathrm{~mm})$. To secure the electrode at depth, the surgeon knots the electrode itself and then sutures it to the skin with a 3-0 nylon figure-of-eight stitch (Fig. 1F).

\section{Results}

Between 2015 and 2020,58 patients underwent 63 SEEG procedures. The basic demographic and surgical details of three groups of patients are presented based on implantation technique: CRW frame with bolted electrodes, ROSA with bolted electrodes only, and ROSA with at least one boltless electrode (Table 1). There were no significant dif- ferences in sex, presence of prior cranial surgery, number of electrodes, or side of surgery between the groups of patients. There was a nonsignificant trend toward decreased age in the patients with at least one boltless electrode.

A total of 793 electrodes were placed, of which 25 $(3.15 \%)$ were boltless. Error data in at least one of the three error measurements were available for 783/793 electrodes (98.7\%). Statistical analysis of the error measurements was performed between the three groups of electrodes (CRW frame and bolts, ROSA and bolts, and ROSA without bolts; Fig. 2 and Supplementary Table 1). The lateral error at target was significantly different between groups and was greatest in the CRW group, intermediate in the ROSA bolted group, and least in the ROSA boltless group (Fig. 2A). There were no differences between groups for the depth error at target or the error at entry, although there was a slight trend toward more depth error in the boltless group (mean values: ROSA boltless, $3.40 \mathrm{~mm}$; ROSA bolted, $2.01 \mathrm{~mm}$; and CRW, bolted $2.59 \mathrm{~mm}$; Fig. 2B and C). For the boltless group, the largest errors for entry, lateral target, and depth 
were $2 \mathrm{~mm}, 4 \mathrm{~mm}$, and $11 \mathrm{~mm}$, respectively. The percentage of electrodes with significant lateral target errors was calculated for the three groups of electrodes, divided into the following three magnitudes: 5-7 mm, 8-10 mm, and > $10 \mathrm{~mm}$ (Fig. 2D). Note that there were no significant lateral target errors in the boltless group. Statistical analysis was not performed on this set of data.

Ten patients received boltless electrodes, receiving an average of 2.5 boltless electrodes per patient (range 1-5; Fig. 3A and B and Supplementary Table 2). The vast majority $(23 / 25,92 \%)$ of boltless electrodes were placed due to inadequate skull thickness at the planned entry point, due to either thin native skull $(22 / 25)$ or thin skull at the edge of a prior craniotomy $(1 / 25)$. Most of these electrodes were placed in the squamous portion of the temporal bone (Fig. $3 \mathrm{C})$. The mean $( \pm \mathrm{SD})$ thickness of the skull at the entry point for boltless leads was $1.85 \pm 0.72 \mathrm{~mm}$ (range 0.5-4.1 $\mathrm{mm}$; Fig. 2D). The final two boltless electrodes were placed to avoid discomfort from a bolt protruding from the back of the head (sampling of the calcarine cortex; Fig. 4).

\section{Discussion}

SEEG is an increasingly popular surgical modality for localizing the EZ. Various techniques are used for electrode placement, but, to our knowledge, this is the first description of SEEG electrode placement without the use of anchor bolts in patients. A recent cadaveric study compared the implantation accuracy of two SEEG methods using the ROSA robot: "technique 1" using bolts and external stylets and "technique 2" without bolts. The authors' primary analysis showed entry errors of 0.91 and $1.83 \mathrm{~mm}(\mathrm{p}<0.001)$ and target errors of 1.45 and $4.32 \mathrm{~mm}$ $(p<0.001)$ for techniques 1 and 2 , respectively. Their secondary analysis also reported that orthogonal trajectories are more accurate than oblique, and deeper implantations were less accurate for electrodes placed without a guiding bolt or external stylet. ${ }^{26}$ Although their study showed decreased accuracy for boltless electrodes, one key difference in technique is our use of external stylets to create a track through the brain prior to electrode implantation.

Our mean entry point errors were similar between all three implantation methods, with an overall mean error of $1.14 \mathrm{~mm}$. This error rate is similar to the mean entry error of $1.2 \mathrm{~mm}$ reported in a recent study from the Cleveland Clinic of SEEG using the ROSA robot. ${ }^{27}$ Our lateral target errors were statistically smaller with boltless electrodes, although clinically equivalent.

Significant lateral target point errors $(\geq 5 \mathrm{~mm})$ were present in $5.7 \%$ of electrodes with anchor bolts placed with ROSA. There were no lateral target errors of $4 \mathrm{~mm}$ or more for the boltless leads. Gross et al. reported a $12 \%$ rate of target errors with greater than $10 \mathrm{~mm}$ deviation in a study using frameless stereotaxy with depth electrodes placed either through burr holes or in the setting of craniotomy for grid placement. ${ }^{28}$ Miller et al. reported significant error rates of $13 \%$ for SEEG electrodes deviating more than $3 \mathrm{~mm}$ from the target using the ROSA system. ${ }^{29}$ Several studies have reported accuracies using different implantation techniques, including a median target error of $2.69 \mathrm{~mm}$ using a Talairach frame,${ }^{17}$ a median target er-
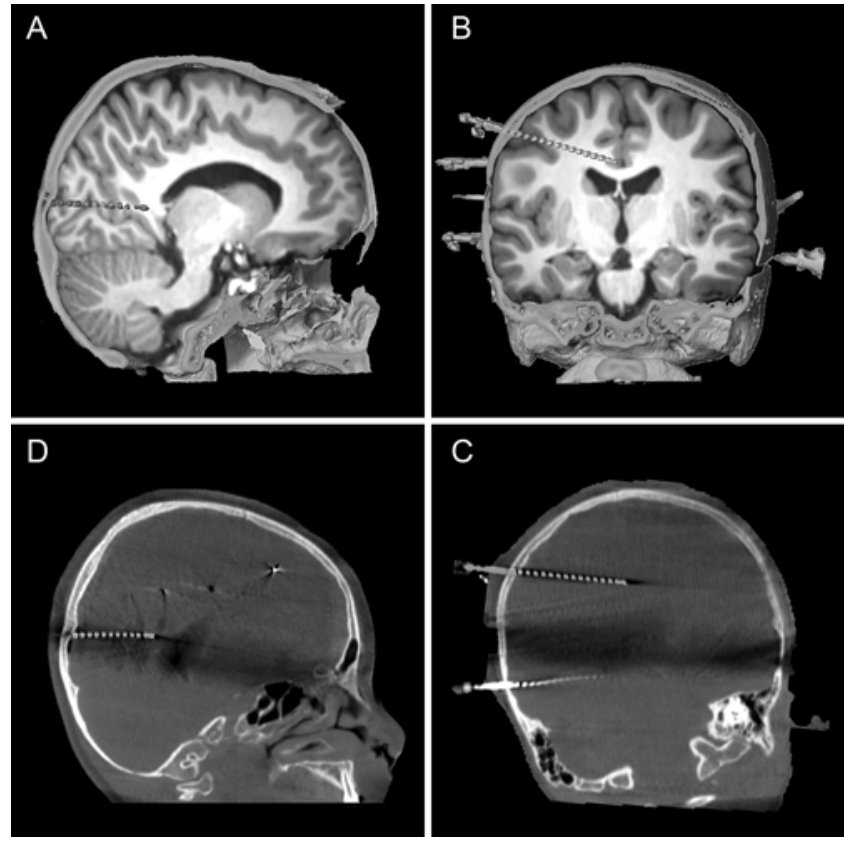

FIG. 4. A 9-year-old girl underwent ROSA SEEG implantation of 10 bolted electrodes (orange) and 2 boltless electrodes (blue) in her occipital bone to avoid pain from bolts when resting in bed. A and B: O-arm images merged to the preoperative MRI study. C and D: Postoperative O-arm scan is shown. In all panels, electrodes are highlighted with color. Figure is available in color online only.

ror of $5.19 \mathrm{~mm}$ using frameless stereotaxy for depth electrodes placed through a burr hole or craniotomy, ${ }^{28}$ and a mean radial error of $1.75 \pm 0.94 \mathrm{~mm}$ using robotic guidance with the ROSA platform. ${ }^{30}$ The various techniques and heterogeneous reporting make it difficult to directly compare our data.

We measured the skull thickness for the boltless electrodes and found an average thickness of $1.85 \mathrm{~mm}$ (range $0.5-4.1 \mathrm{~mm}$ ). This is considerably thinner than the median skull thickness of $5.04 \mathrm{~mm}$ measured in a series of bolted electrodes in 482 patients aged $2-56$ years. ${ }^{17}$

The rationales for using the boltless technique in this series include thin bone at the entry site (usually at the temporal squamosa), entry site close to a prior craniotomy defect where breakout into the defect can occur, and entry site on the back of the head. The boltless technique could also be considered for electrode entry points very close to one another that may cause bolts to collide. Our current practice for implanting boltless electrodes is made intraoperatively when the bone thickness is less than $2 \mathrm{~mm}$ and in some cases when the bone is $2-3 \mathrm{~mm}$ thick.

The limitations of this study include its retrospective nature and the limited number of boltless electrodes ( $\mathrm{n}=$ 25) compared with bolted electrodes for which measurements were available $(n=765)$. Furthermore, depth error was measured on imaging performed immediately after the procedure. Because the electrodes are secured to the skin surface rather than to the bone, the accuracy may be affected by scalp swelling that develops later in the course. Further study is needed to fully understand the safety, accuracy, and utility of boltless SEEG electrodes. 


\section{Conclusions}

Boltless SEEG electrodes can be placed through thin bone, adjacent to a cranial defect, or in the occiput with equivalent accuracy to electrodes placed with anchor bolts.

\section{References}

1. Ngugi AK, Bottomley C, Kleinschmidt I, et al. Estimation of the burden of active and life-time epilepsy: a meta-analytic approach. Epilepsia. 2010;51(5):883-890.

2. World Health Organization. Epilepsy: A Public Health Imperative. WHO; 2019.

3. Fiest KM, Sauro KM, Wiebe S, et al. Prevalence and incidence of epilepsy: a systematic review and meta-analysis of international studies. Neurology. 2017;88(3):296-303.

4. Kalilani L, Sun X, Pelgrims B, et al. The epidemiology of drug-resistant epilepsy: a systematic review and meta-analysis. Epilepsia. 2018;59(12):2179-2193.

5. Kwan P, Brodie MJ. Early identification of refractory epilepsy. N Engl J Med. 2000;342(5):314-319.

6. Ramos-Lizana J, Rodriguez-Lucenilla MI, Aguilera-López P, et al. A study of drug-resistant childhood epilepsy testing the new ILAE criteria. Seizure. 2012;21(4):266-272.

7. Aaberg KM, Bakken IJ, Lossius MI, et al. Short-term seizure outcomes in childhood epilepsy. Pediatrics. 2018;141(6): e20174016.

8. Wirrell E, Wong-Kisiel L, Mandrekar J, Nickels K. Predictors and course of medically intractable epilepsy in young children presenting before 36 months of age: a retrospective, population-based study. Epilepsia. 2012;53(9):1563-1569.

9. Zhang J, Liu W, Chen H, et al. Multimodal neuroimaging in presurgical evaluation of drug-resistant epilepsy. Neuroimage Clin. 2013;4:35-44.

10. Gadgil N, LoPresti MA, Muir M, et al. An update on pediatric surgical epilepsy: Part I. Surg Neurol Int. 2019;10:257.

11. Lüders HO, Najm I, Nair D, et al. The epileptogenic zone: general principles. Epileptic Disord. 2006;8(suppl 2):S1-S9.

12. Pondal-Sordo M, Diosy D, Téllez-Zenteno JF, et al. Usefulness of intracranial EEG in the decision process for epilepsy surgery. Epilepsy Res. 2007;74(2-3):176-182.

13. Talairach J, Bancaud J, Bonis A, et al. Functional stereotaxic exploration of epilepsy. Confin Neurol. 1962;22:328-331.

14. Murphy MA, O'Brien TJ, Cook MJ. Insertion of depth electrodes with or without subdural grids using frameless stereotactic guidance systems - technique and outcome. $\mathrm{Br} \mathrm{J}$ Neurosurg. 2002;16(2):119-125.

15. Mehta AD, Labar D, Dean A, et al. Frameless stereotactic placement of depth electrodes in epilepsy surgery. J Neurosurg. 2005;102(6):1040-1045.

16. Ortler M, Sohm F, Eisner W, et al. Frame-based vs frameless placement of intrahippocampal depth electrodes in patients with refractory epilepsy: a comparative in vivo (application) study. Neurosurgery. 2011;68(4):881-887.

17. Cardinale F, Cossu M, Castana L, et al. Stereoelectroencephalography: surgical methodology, safety, and stereotactic application accuracy in 500 procedures. Neurosurgery. 2013; 72(3):353-366.

18. Serletis D, Bulacio J, Bingaman W, et al. The stereotactic approach for mapping epileptic networks: a prospective study of 200 patients. J Neurosurg. 2014;121(5):1239-1246.

19. Ollivier I, Behr C, Cebula H, et al. Efficacy and safety in frameless robot-assisted stereo-electroencephalography (SEEG) for drug-resistant epilepsy. Neurochirurgie. 2017;63(4): 286-290.
20. Eljamel MS. Robotic application in epilepsy surgery. Int $J$ Med Robot. 2006;2(3):233-237.

21. Musolino A, Tournoux P, Missir O, Talairach J. Methodology of "in vivo" anatomical study and stereo-electroencephalographic exploration in brain surgery for epilepsy. J Neuroradiol. 1990;17(2):67-102.

22. Gonzalez-Martinez J, Mullin J, Vadera S, et al. Stereotactic placement of depth electrodes in medically intractable epilepsy. J Neurosurg. 2014;120(3):639-644.

23. Isnard J, Taussig D, Bartolomei F, et al. French guidelines on stereoelectroencephalography (SEEG). Neurophysiol Clin. 2018;48(1):5-13.

24. Mirandola L, Mai RF, Francione S, et al. Stereo-EEG: Diagnostic and therapeutic tool for periventricular nodular heterotopia epilepsies. Epilepsia. 2017;58(11):1962-1971.

25. Bourdillon P, Isnard J, Catenoix H, et al. Stereo-electroencephalography-guided radiofrequency thermocoagulation: from in vitro and in vivo data to technical guidelines. World Neurosurg. 2016;94:73-79.

26. Jones JC, Alomar S, McGovern RA, et al. Techniques for placement of stereotactic electroencephalographic depth electrodes: comparison of implantation and tracking accuracies in a cadaveric human study. Epilepsia. 2018;59(9):1667-1675.

27. González-Martínez J, Bulacio J, Thompson S, et al. Technique, results, and complications related to robot-assisted stereoelectroencephalography. Neurosurgery. 2016;78(2): 169-180.

28. Gross RE, Sung EK, Mulligan P, et al. Accuracy of frameless image-guided implantation of depth electrodes for intracranial epilepsy monitoring. J Neurosurg. 2020;132(3):681-691.

29. Miller BA, Salehi A, Limbrick DD Jr, Smyth MD. Applications of a robotic stereotactic arm for pediatric epilepsy and neurooncology surgery. J Neurosurg Pediatr. 2017;20(4): 364-370.

30. Ho AL, Muftuoglu Y, Pendharkar AV, et al. Robot-guided pediatric stereoelectroencephalography: single-institution experience. J Neurosurg Pediatr. 2018;22(5):489-496.

\section{Disclosures}

The authors report no conflict of interest concerning the materials or methods used in this study or the findings specified in this paper.

\section{Author Contributions}

Conception and design: Karsonovich. Acquisition of data: Karsonovich, Alexander. Analysis and interpretation of data: all authors. Drafting the article: O'Neill, Karsonovich, Alexander. Critically revising the article: O'Neill, Karsonovich, Alexander. Reviewed submitted version of manuscript: O'Neill, Karsonovich. Statistical analysis: O’Neill, Alexander, Graber. Study supervision: O’Neill, Alexander.

\section{Supplemental Information \\ Online-Only Content}

Supplemental material is available with the online version of the article.

Supplementary Tables 1 and 2. https://thejns.org/doi/suppl/ 10.3171/2020.7.PEDS20403.

\section{Correspondence}

Brent R. O’Neill: Children's Hospital of Colorado, Aurora, CO. brent.oneill@childrenscolorado.org. 